\title{
Research on the Connotation and Development Strategy of Chinese Campus Football Culture from the Perspective of the Integration of Sports and Education
}

\author{
Hongke Zhao, Hua Meng \\ School of Physical Education, Shandong Normal University, Ji'nan, China \\ Email: 844254530@qq.com
}

How to cite this paper: Zhao, H. K., \& Meng, H. (2021). Research on the Connotation and Development Strategy of Chinese Campus Football Culture from the Perspective of the Integration of Sports and Education. Open Journal of Social Sciences, 9, 157-163.

https://doi.org/10.4236/jss.2021.93010

Received: October 15, 2020

Accepted: March 9, 2021

Published: March 16, 2021

\begin{abstract}
To promote the development of campus football work and better develop campus football culture, by using the methods of literature research and logical analysis, on the basis of combing the connotation of campus football culture, according to the national sports and education integration policy, the study makes an in-depth discussion on the connotation of campus football culture. The study shows that campus football culture is In the campus field, with the main goal of enjoying fun, strengthening physique, perfecting personality and tempering will, it is a combination of material culture, spiritual culture, behavior culture and system culture formed in a series of practical activities related to football. Through the analysis of the current predicament of campus football culture in China, this study puts forward the development strategy of campus football culture, which provides certain theoretical construction significance for the development of campus football culture in the future.
\end{abstract}

\section{Keywords}

Integration of Sports and Education, Campus Football Culture, Development Strategy

\section{Introduction}

The State Council promulgated the General Plan for the Reform and Development of Chinese Football (The General Plan) in March 2015, which pointed out that all localities should actively promote the popularization of campus 
football, promote the common development of students' basic subjects learning and sports skills, and promote the large-scale growth of young football talent (The State Council, 2015). In July 2015, the Ministry of Education and other six departments promulgated the "Implementation Opinions on Speeding Up the Development of Youth Campus Football", which pointed out that our country should improve the popularization level of campus football and cultivate culture to consolidate and popularize. Take diversified football activities as an important part of the construction of campus football culture (Ministry of Education, 2015). These two documents basically determine the overall strategic layout of the development of campus football in our country. he State Administration of Sports and the Ministry of Education jointly issued the Opinions on Deepening the Integration of Sports and Education and Promoting the Healthy Development of Teenagers, which points out that the integration of sports and education is to integrate the training system of competitive sports talents into the national education system, and school physical education plays a very important role in the process of sports and education integration. The integration of sports and education is conducive to promoting the coordinated development of students' basic subjects learning and physical exercise, and training socialist builders and successors with all-round development of morality, intelligence, physique, aesthetics and labor (The State General Administration of Sports and the Ministry of Education, 2020). According to the document, the important foothold of the development of campus football in our country lies in the construction and development of campus football culture. In the future, the important task of the development of youth campus football in our country is to enjoy football fun, strengthen students' physique, improve students' personality, temper teenagers' will, and develop campus football culture. For the first four tasks, based on the long-term research on hot issues of campus football and the academic accumulation of experts, it can be implemented more perfectly. However, at present, the construction of campus football culture in China is still in its infancy. Due to the lack of experience in the construction of campus football culture, Chinese scholars have different understandings and cognition about the connotation and characteristics of campus football culture from different perspectives and levels.

Based on the construction and development of campus football culture, which is the important foothold of the development of campus football, this paper combs and probes into the understanding of campus football culture by different scholars, and summarizes the difficulties of campus football culture. This paper puts forward the corresponding strategies for the development of campus football culture to better promote the construction of campus football culture.

\section{Discussion on the Connotation of Campus Football Culture}

By sorting out the previous literature, it can be seen that although different scho- 
lars have different definitions of campus football culture, the definition of campus football culture emphasizes the special area of "campus" and explains it according to the basic characteristics of football culture. Campus football culture is the sum total of material culture, spiritual culture, system culture and behavior culture related to campus football, and it is a cultural unity composed of them (Hou et al., 2013). Material culture is the basic element of campus football culture, which is the field equipment and teachers related to football; spiritual culture is the goal and direction, which carries the expectations and ideals of teachers and students for football; institutional culture is the fundamental guarantee, and its guarantee mainly depends on the documents guided by the country; behavior culture is the norm and the core element, and it is the concrete reflection of students' participation in campus football practice. Campus football culture is on campus to enrich the cultural life of students after school to meet students "interest in football, enhance physical fitness of students, improve students" skills and knowledge of football as the core goal, the school facilities during the construction of basic football, soccer appreciation, the sum of all material culture, spiritual culture, institutional culture and behavior culture of football soccer training, soccer games, teaching soccer, football and football management and other propaganda activities in the process of formation. Compared to this sort of connotation than their predecessors, increasing the clarity of objectives, activities will conduct more specific (Zhang \& Wu, 2016). Campus football culture is a process of a series of campus football practice activities carried out by teachers and students in campus within the scope of campus this area, taking football activities as the link, taking campus football teaching, football training, football matches, football clubs as carriers (Zhao, 2016). Campus football has an important influence on campus culture. First of all, campus football can enrich campus culture, which is conducive to the construction and inheritance of campus football culture; secondly, the construction of campus football culture can enhance students' team consciousness and cooperative spirit. Campus football culture is a lifestyle system with a group shared tendency, which is built on the campus field, takes football as the theme and inherits from generation to generation (Zhang, 2018). The connotation was defined on the basic of combing the concept and characteristics of culture. In this connotation, campus football culture should have the following four characteristics at the same time, that is, inheritance, group, constraint, implicit and explicit. Through the above analysis of the connotation of campus football culture, scholars and experts have emphasized the special field of "campus", and elaborated according to the characteristics of football culture. Based on the discussion and understanding of the above scholars, campus football culture in this study can be defined as in the campus field, with the main goal of enjoying fun, strengthening physique, perfecting personality and tempering will, it is a combination of material culture, spiritual culture, behavior culture and system culture formed in a series of practical activities related to football. 


\section{The Predicament of the Development of Campus Football Culture}

\subsection{Lack of Experience in Campus Football Work}

At present, the work of campus football in China is still in the stage of building national football characteristic schools. According to Wang Dengfeng, director of the Sports Health and Arts Education Department of the Ministry of Education, since the issuance of the "The General Plan" issued by the Ministry of Education in 2015, 24,126 campus football characteristic schools have been selected and identified, 38 prefectural, municipal and provincial campus football experimental areas have been built, and 24,126 campus football pilot counties (districts) have been identified (Wang, 2019). It can be seen that the number of schools with campus football characteristics is growing, but ensuring quality is still a difficult problem. Due to the weak rigor of the audit procedures of the relevant departments, false or concealed reports may occur in some areas in the declaration process (Yang et al., 2020). In order to make a successful declaration, schools in various prefectures and cities have focused on football infrastructure and equipment. However, the experience in the construction of campus football culture and the development of campus football activities is not rich enough, and there are few schools that can form a fine tradition of football culture.

\subsection{Group Identity Needs to Be Improved}

For most schools, campus football work is carried out to respond to the national call, not to take the initiative to participate in (Zhang, 2018). The main work of most schools is still implemented in the teaching of basic subjects, so it is difficult to achieve the ideal state of the integration of sports and education. In the process of carrying out campus football activities, it is very difficult for students to participate in all the activities. The head teacher should focus on the academic achievements of the class, the prejudice of students' parents to football, and the school's concern about students' personal safety accidents, which lead to the recognition of various groups on campus for campus football needs to be improved. Although the national policy strongly supports the campus football work and invests human, material and financial resources, it is difficult to achieve results in the short term.

\subsection{Lack of Students' Initiative}

Students can actively participate in football is an important symbol of the formation of the campus football culture. However, the reality is that students are passively involved in campus football activities. The school requires students to participate in football, but it does not consider how to stimulate the internal drive of students. Students are forced to participate, which makes it difficult for them to have interest in continuing to explore the mystery of football, and gradually lose their confidence in football. 


\subsection{Lack of Means of Development}

Currently, local schools only focus on the teaching of football skills. The study of football skills is indeed very important to students, but students blindly learn skills, it is difficult to jump out of the "textbook" thinking, can not really enjoy the fun and charm of football. At the same time, a single means of development ignores the happiness that football brings to students, which can not improve students' physical quality and health level, let alone temper students' will quality and sound personality.

\section{Strategies for the Development of Campus Football Culture in China}

\subsection{Improving the Group Recognition of Campus Football}

Through the analysis of some domestic football characteristic schools, it is found that, first of all, these football characteristic schools regard football as their traditional characteristics and put it on the key development projects of the school. Secondly, some football characteristic schools can combine the skill teaching of football with the concept of educating people, so that football is not only a sport but also a vivid life lesson. Third, the leaders of various departments of these football characteristic schools attach great importance to football, respond positively to the national call, and require all head teachers and PE teachers to participate in various campus football activities one after another, thus forming the group identity of the whole school staff to campus football. In the above three aspects, the third one is the core of campus football. Therefore, we first need all the leading departments of the school to attach great importance to it, which is the core of the development of campus football culture, if we want to develop campus football culture.

\subsection{Stimulate Students' Interest}

The ultimate beneficiaries of the development of campus football culture are students. Cultivating students' interest and forming a good campus football atmosphere is the key to the development of campus football culture. First of all, it is suggested that PE teachers should enrich the teaching content and arouse the enthusiasm of students in PE class. In addition to simple skill teaching, the teaching content of physical education should also add football games, the popularization of world football culture, football history education and so on, so as to let students understand football from different perspectives and stimulate students' interest in football. With these ways, not only opened up the field of knowledge of students, but also to create a good campus football culture. Secondly, we should innovate football teaching methods, use multimedia, picture and video teaching methods to carry out diversified and personalized teaching for students, strengthen the communication between teachers and students, and stimulate students' initiative to participate in campus football. 


\subsection{Optimize the Means of Development to Form the Traditional Characteristics of the Campus}

The methods of the development of campus football culture should be diversified. First of all, it is suggested to hold campus football competitions at all levels. Football match is an important way to stimulate students' team consciousness and learning ability. In both intra-school and inter-school competitions, students will actively make efforts in order to show themselves on the field and win. Therefore, football skills, tactics, team consciousness, hard-working spirit and the consciousness of abiding by the rules can be well inspired, so as to promote the all-round development of students morally, intellectually, physically and physically. Secondly, it is suggested that the school should carry out rich and colorful campus football theme activities. For example, football rhythmic exercises at recess, introduction of students' favorite football stars at theme class meetings, appreciation of important matches, and so on. This series of activities help to form the traditional characteristics of campus football culture, help students to learn and accumulate their own football skills and tactics, and continue to practice and improve in future training and competitions, in order to stimulate students' interest, to lay the foundation for a better campus football culture atmosphere.

\section{Conclusion}

The development of campus football culture is an important foundation of campus football work. At present, campus football work in China is in full swing. Sorting out and clarifying the connotation of campus football culture is conducive to the better development of campus football work in the future. According to the national sports and education integration policy, the study makes an in-depth discussion on the connotation of campus football culture. The study shows that campus football culture is in the campus field, with the main goal of enjoying fun, strengthening physique, perfecting personality and tempering will, it is a combination of material culture, spiritual culture, behavior culture and system culture formed in a series of practical activities related to football. At the same time, this paper discusses the difficulties in the development of campus football culture in China, such as the development of campus football is starting, the group identity needs to be improved, the students' initiative is insufficient, and the development means are single. In view of the above difficulties, this paper puts forward some development strategies, such as improving the identity of campus football groups, stimulating students' interest, optimizing the means of development, forming the traditional characteristics of campus and so on. This connotation and development strategy can make campus football work more efficient, and also provide some theoretical significance for the development of campus football culture in the future.

\section{Acknowledgements}

The authors gratefully acknowledge the valuable contributions of my tutor pro- 
fessor Meng Hua.

\section{Conflicts of Interest}

The authors declare no conflicts of interest regarding the publication of this paper.

\section{References}

Hou, X. H., Xue, L., \& Chen, Y. Z. (2013). Research on the Connotation of Campus Football Culture. Sports Culture Guide, 6, 107-110.

Ministry of Education (2015). Opinions on Speeding up the Development of Youth Campus Football. http://www.gov.cn/xinwen/2015-08/13/content 2912131.html

The State Council (2015). Circular on Issuing the General Plan for the Reform and Development of Chinese Football. http://www.gov.cn/zhengce/content/2015-03/16/content 9537.html

The State General Administration of Sports and the Ministry of Education (2020). Opinions on Deepening the Integration of Sports and Education and Promoting the Healthy Development of Teenagers. http://www.gov.cn/xinwen/2020-09/21/content 5545376.html

Wang, D. F. (2019). 2025 National Campus Soccer Feature School Will Reach 50,000 Schools. http://www.gov.cn/xinwen/2019-07/29/content 5416098.htm.

Yang, X. N., Wu, L. F., \& Li, S. N. (2020). Basic Problems and Countermeasures of Campus Football Pilot County (District) Management in China. Journal of Shenyang Sport University, 5, 40-48.

Zhang, W. D, \& Wu, F. (2016). The Types and Construction Methods of Campus Football Culture. Sports Culture Guide, 5, 150-152.

Zhang, X. G. (2018). New Interpretation of the Connotation and Construction Strategies of Campus Football Culture from the Perspective of Cultural Characteristics. Journal of Shenyang Sport University, 4, 59-63.

Zhao, C. Y. (2016). Influence of Campus Culture and Construction of Football Strategy. Journal of Educational Institute of Jilin Province, 12, 169-171. 